\title{
Acute respiratory failure caused by neglected giant substernal nontoxic goiter
}

\author{
Insuficiência respiratória aguda resultante de bócio \\ atóxico mergulhante gigante negligenciado
}

Orestis loannidis', Eleftheria Dalampini' ${ }^{2}$ Stavros Chatzopoulos',

Anastasios Kotronis', George Paraskevas ${ }^{3}$, Athina Konstantara',

Nikolaos Papadimitriou', Apostolos Makrantonakis', Emmanouil Kakoutis'

\section{SUMMARY}

Substernal goiter is usually defined as a goiter in which the thyroid mass has descended the plane of the thoracic inlet or if more than $50 \%$ of the thyroid mass is located below the thoracic inlet. Substernal goiters may be asymptomatic or may present with symptoms caused by compression of adjacent organs. Acute respiratory failure is rare in cases of substernal goiter. In cases of symptomatic substernal goiter the treatment is surgical by thyroidectomy. We present a rare case of a giant substernal nontoxic goiter which caused acute respiratory failure which was treated by urgent thyroidectomy through a T-incision. Arq Bras Endocrinol Metab. 2011;55(3):229-32

\author{
First Surgical Department, \\ General Regional Hospital "George \\ Papanikolaou", Thessaloniki, Greece \\ 2 Department of Anesthesiology, \\ General Regional Hospital "George \\ Papanikolaou", Thessaloniki, Greece \\ ${ }^{3}$ Department of Anatomy, Medical \\ School, Aristotle University \\ of Thessaloniki, Greece
}

\section{SUMÁRIO}

Geralmente se define o bócio mergulhante como o bócio em que a massa da tireoide descende ao plano da cavidade torácica ou mais do que $50 \%$ da massa tireoidiana se localiza abaixo da cavidade tireoidiana. $O$ bócio mergulhante pode ser assintomático ou apresentar sintomas resultantes da compressão de órgãos adjacentes. A insuficiência respiratória aguda é rara nos casos de bócio mergulhante. Nos casos de bócio mergulhante sintomático, o tratamento indicado é cirúrgico, por tireoidectomia. Nesse relato, descreveu-se um caso raro de bócio atóxico mergulhante gigante negligenciado que resultou em insuficiência respiratória aguda e foi tratado com tireoidectomia de emergência com incisão em T. Arq Bras Endocrinol Metab. 2011;55(3):229-32

\author{
Correspondence to: \\ Orestis loannidis \\ Alexandrou Mihailidi, 13, \\ 54640 - Thessaloniki, Greece \\ telonakos@hotmail.com \\ Received on Jan/12/2011 \\ Accepted on Mar/8/2011
}

\section{INTRODUCTION}

$\mathrm{T}$ he definition of goiter refers to a thyroid gland weighing more than 40 grams or enlarged to twice its normal size (1). However, the definition of substernal goiter is not clear and there is a variety of definitions depending on the individual surgeon (2). To date, 10 different definitions have been given (2). Usually, substernal goiter is defined as a goiter in which the thyroid mass has descended the plane of the thoracic inlet or if more than $50 \%$ of the thyroid mass is located below the thoracic inlet $(1,3)$. Due to the variety of definitions the percentage of substernal goiters varies from $2 \%$ to $20 \%$ of all patients undergoing thyroidectomy
$(1,3)$. The symptoms are usually caused by compression of the adjacent structures including the trachea, esophagus, and superior vena cava $(1,4,5)$. However, airway compression may rarely lead to severe or life threatening asphyxia $(1,4)$. We present a case of a giant substernal nontoxic goiter which caused acute respiratory failure.

\section{CASE REPORT}

A 51-year-old female was transferred to the emergency department of our hospital intubated because of acute respiratory failure. Anesthesia was maintained with propofol and fentanyl. The patient was hemodynamically 
stable with blood pressure of $95 / 65 \mathrm{mmHg}$ and a heart rate of 90 beats per minute. Her temperature was of $37.2^{\circ} \mathrm{C}$. Prior to intubation the patient also presented cyanosis and edema of the head and upper extremities.

The patient had morbid obesity (weight $120 \mathrm{~kg}$, height $160 \mathrm{~cm}$, body mass index 46.87 ) and a neglected goiter with gradual growth over a 25 -year period despite the fact that the she was receiving L-thyroxine sodium $0.15 \mathrm{mg}$ daily and was euthyroid. The patient's medical history revealed arterial hypertension, diabetes mellitus type 2 , and limited physical activity in the 2 previous years. In the prior month the patient complained about hoarseness and dyspnea especially in the supine position. Also, the patient complained about fatigue, mild dysphagia, and low grade fever in the last 3 days.

Physical examination revealed a large cervical nodular goiter extending downwards to the mediastinum (Figure 1). Blood gas analysis showed moderate oxygenation, as in $\mathrm{FiO}_{2} 100 \%$ the patient had $\mathrm{pH} 7.44$, $\mathrm{pCO}_{2} 45 \mathrm{mmHg}, \mathrm{pO}_{2} 98 \mathrm{mmHg}$, and $\mathrm{SO}_{2} 94 \%$. Laboratory examination revealed leukocytosis with WBC $11.200 \times 10^{6} / \mathrm{mL}$ (88.7\% neutrophils), hyperglycemia of $307 \mathrm{mg} / \mathrm{dL}$ blood glucose, and a slightly elevated SGOT (57 IU/L). All other laboratory examinations were within normal limits.

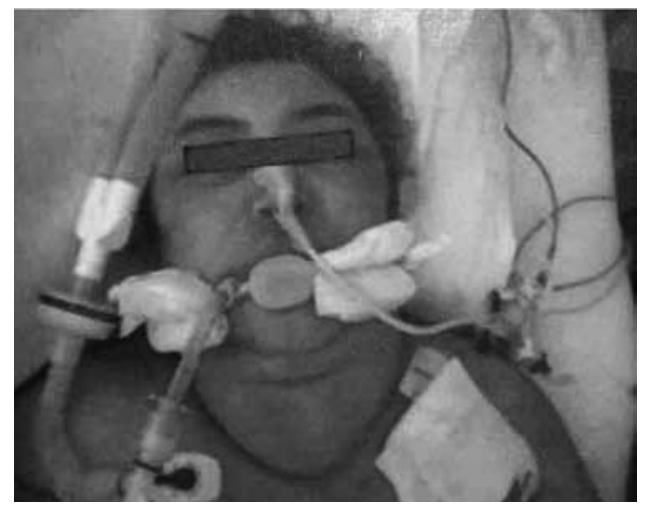

Figure 1. A large cervical goiter extending towards the thoracic inlet.
Chest X-ray revealed tracheal repulsion. Cervical and thoracic CT showed a large nodular substernal goiter, especially of the left lobe, which repelled the large vessels, caused tracheal pressure and deviation, and extended the inferior and anterior of the tracheal carina to the esophageal sulcus of the left lung (Figure 2). Goiter dimensions were of $13 \times 15 \times 19 \mathrm{~cm}$.

The patient was submitted to an urgent total thyroidectomy. Initially, a Kocher incision was performed but due to the large size of the goiter the incision was extended and a T-incision was made including complete median sternotomy (Figure 3). Four pieces were resected weighing a total of 582 grams and measuring from 5.5 to $9.5 \mathrm{~cm}$ (Figure 4). Histopathologic examination revealed adenomatous multinodular goiter.

The patient was transferred to the intensive care unit under inotropic support and with moderate oxygenation. At first, the patient remained hemodynamically unstable with moderate oxygenation as in $\mathrm{FiO}_{2}$ 95\% the patient had $\mathrm{pH} 7.42, \mathrm{pCO}_{2} 37 \mathrm{mmHg}, \mathrm{pO}_{2}$ $79 \mathrm{mmHg}$, and $\mathrm{SO}_{2} 92 \%$. In the $2^{\text {nd }}$ postoperative day cyanosis and edema of the head and upper extremities subsided. The echocardiography performed revealed right heart failure and the abdominal echo showed fatty infiltration of the liver. During the next days the patient became hemodynamically stable and gained consciousness but remained intubated because the efforts to extubate her were unsuccessful and she did not maintain good oxygenation. On the $9^{\text {th }}$ postoperative day the patient presented high fever $\left(39.7^{\circ} \mathrm{C}\right)$ and respiratory distress. The chest X-ray demonstrated pneumonia and cultures revealed infection by Acinetobacter baumannii. The patient was once again placed under inotropic support with noradrenaline but deteriorated day-by-day and developed multiple organ dysfunction syndrome due to sepsis. The patient died on the $17^{\text {th }}$ postoperative day.
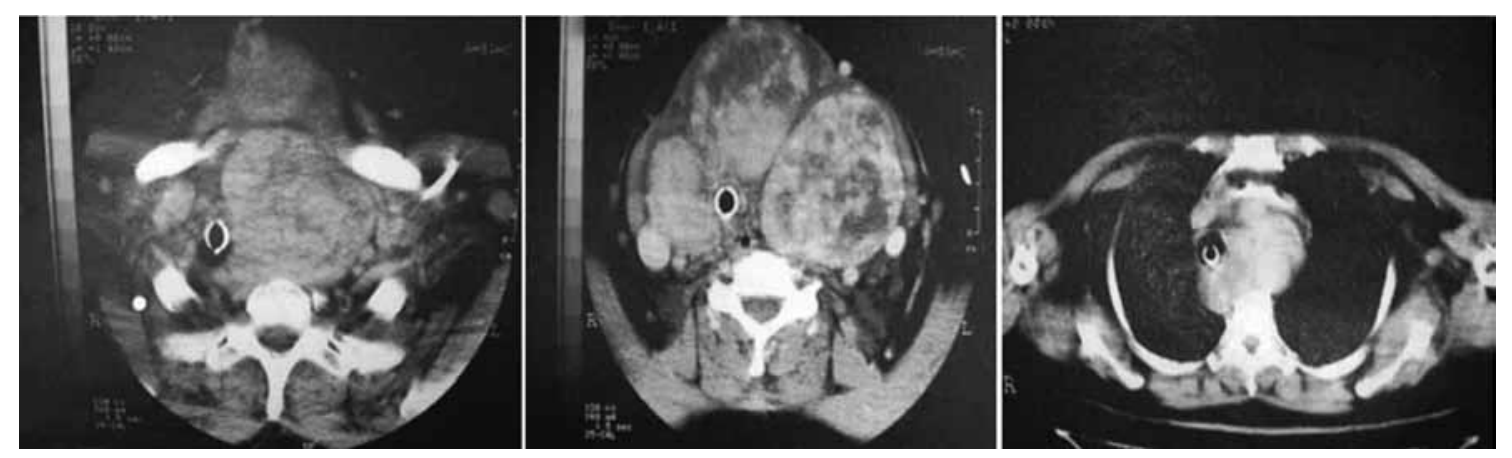

Figure 2. CT scan showing the large substernal goiter compressing and deviating the trachea. 

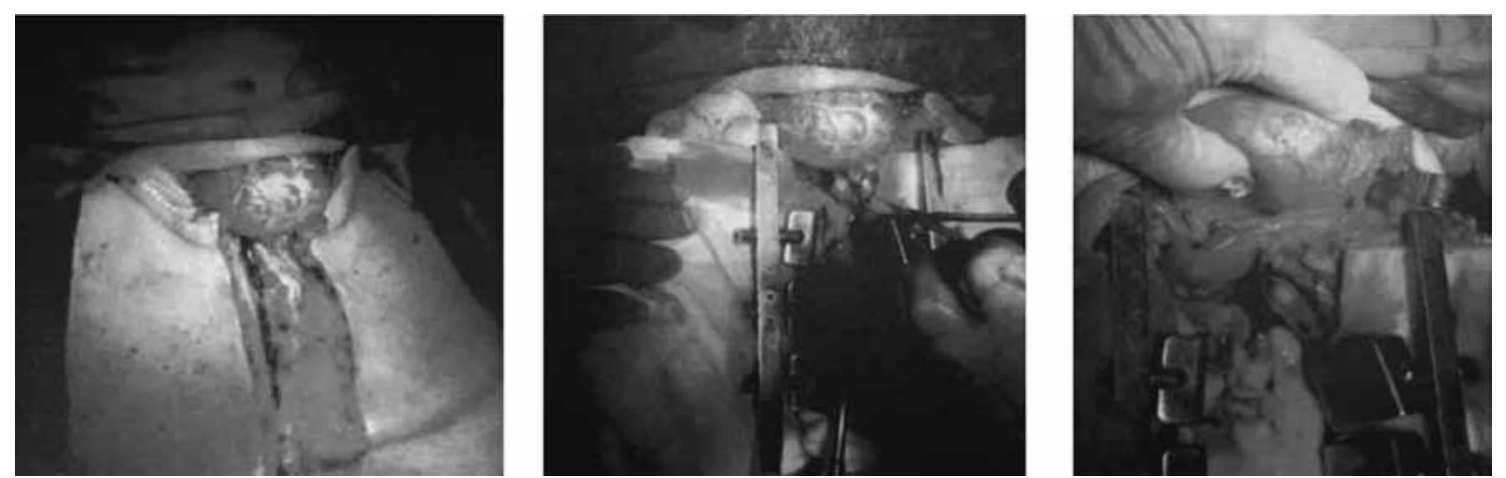

Figure 3. Intraoperative images showing the goiter extending to the mediastinum.

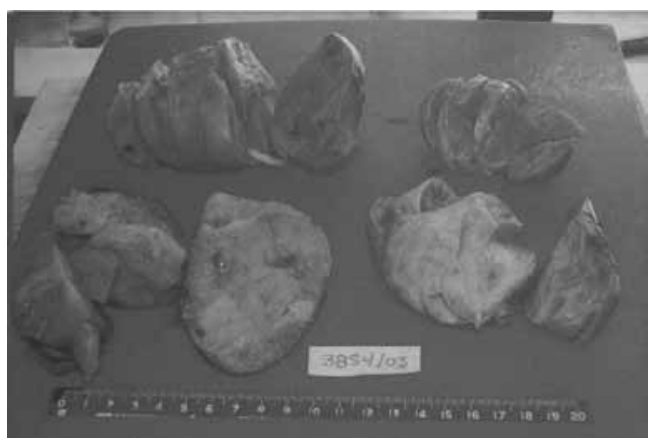

Figure 4. Goiter, surgical specimen.

\section{DISCUSSION}

Substernal goiters are classified as primary or secondary $(1,3)$. Primary substernal goiters account for less than $1 \%$ and derive from ectopic thyroid tissue in the mediastinum $(1,4)$. On the other hand, secondary substernal goiters, which account for $99 \%$, are characterized by the downward growth of cervical thyroid tissue into the thoracic inlet $(1,4)$, and continue to receive blood supply form the superior and inferior thyroid arteries (1). These goiters are mostly situated in the anterior mediastinum (85\%-90\%), and can be unilateral or bilateral, growing past the midiline $(1,3,4)$. Only $10 \%-15 \%$ substernal goiters are located in the posterior mediastinum $(1,3,4)$.

Substernal goiters are generally discovered during the fifth and sixth decades of life and have a female predominance (female/male ratio 3:1) $(1,6)$. A variable percent of patients $(15 \%-50 \%)$ are asymptomatic (6), while the most important presented symptoms result from mediastinal compression (5) and especially from tracheal compression (45\%-49.2\%), ranging from mild cough and dyspnea to acute respiratory failure $(1,3,4)$. The incidence of acute airway obstruction caused by benign goiter is low $(0.6 \%)$ and substernal goiters account for the majority of these cases (7). About $10 \%$ of these patients require emergency airway intubation (4), as in the present case. The causes of acute respiratory failure include upper respiratory tract infections resulting in edema and retention of secretions, sudden intrathyroidal hemorrhage, worsening of a medical illness, and tracheal stenosis or collapse (4,7-9). In the present case we believe that the patient suffered from upper airway obstruction because of the giant substernal goiter and also from restrictive lung disease caused by morbid obesity. This pathology combined with a mild upper respiratory tract infection, as indicated by the patient's history, probably lead to acute respiratory failure.

Other symptoms include dysphagia, dysphonia, superior vena cava syndrome, Horner's syndrome, transient ischemic attacks, cerebral edema, and cardiac dysfunction $(1,3,6)$. A neck mass may be palpable, but in $20 \%-30 \%$ of cases the goiter is not palpable or is barely palpable, with most of the thyroid mass positioned in the chest $(1,6)$. Also, about $20 \%$ of the patients present with symptoms of hyperthyroidism (4).

Plain chest radiographs show a mediastinal mass. The CT will show the exact location and extent of the substernal goiter (6). Although substernal goiters represent the most common occurring mass of the superior mediastinum and account for $10 \%-15 \%$ of all space-occupying lesions of the mediastinum, differential diagnosis should be considered for lymphomas, thymomas, pleuropericardial cysts, dermoid cysts, and neurogenic tumors (6).

Medical treatment, including thyroxine and iodine-131, is not particularly useful for substernal goiters (1) and surgery is the treatment of choice for symptomatic goiters (3). While there is no consensus regarding the indications for thyroidectomy, substernal goiter should be treated surgically if it is symptomatic, if it does not respond to medical treatment, to prevent potential acute airway obstruction, especially in patients 
with compromised airflow identified by spirometry, and if malignancy is suspected in order to establish tissue diagnosis $(3,4,6,7)$. The reported risk of malignancy ranges from $4 \%$ to $22 \%$ (3), but recent data suggest that the incidence of cancer in substernal goiters is no higher than in cervical goiters (1). Urgent thyroidectomy while rare is necessitated in cases of airway obstruction, both from benign and malignant causes, venous obstruction, and thyrotoxicosis with physiologic compromise $(7,9,10)$. In cases of airway obstruction partial or total thyroidectomy relieved the symptoms (7). In the present case surgery lead to gradual symptoms subsidence and by the second day edema and cyanosis disappeared and oxygenation was also improved, but due to existing co-morbidities, never reached a satisfying level.

Most substernal goiters can be removed through a Kocher transverse collar incision and the need for an extracervical approach, including sternotomy or thoracotomy, is about $2 \%(1,3)$, which is usually utilized in primary goiters, giant lesions larger than the thoracic inlet, malignancy, and severe intraoperative complications $(1,3)$. The most common surgical complications are injury of the recurrent laryngeal nerve, transient or persistent hypocalcemia and hematoma $(1,3)$ and rarely pneumothorax, pneumonia, postoperative pleural infusion and cervical plexopathy. Emergency thyroidectomy seems to be accompanied by a higher degree of morbidity (10). Tracheomalacia, defined as the softening and floppiness of the trachea, although infrequent may develop in the presence of substernal goiter for more than 5 years significantly compressing the trachea $(1)$.

In conclusion, substernal goiter is usually defined as a goiter in which the thyroid mass has descended the plane of the thoracic inlet or if more than $50 \%$ of the thyroid mass is located below the thoracic inlet. Substernal goiters may be asymptomatic or may present with symptoms caused by compression of adjacent organs. Acute respiratory failure is rare in cases of substernal goiter. In cases of symptomatic substernal goiter the indicated treatment is thyroidectomy.

Disclosure: no potential conflict of interest relevant to this article was reported.

\section{REFERENCES}

1. White ML, Doherty GM, Gauger PG. Evidence-based surgical management of substernal goiter. World J Surg. 2008;32:1285-300.

2. Shaha AR. Substernal goiter: what is in a definition? Surgery. 2010;147:239-40.

3. Agha A, Glockzin G, Ghali N, lesalnieks I, Schlitt HJ. Surgical treatment of substernal goiter: an analysis of 59 patients. Surg Today. 2008;38:505-11.

4. Ket S, Ozbudak O, Ozdemir T, Dertsiz L. Acute respiratory failure and tracheal obstruction in patients with posterior giant mediastinal (intrathoracic) goiter. Interact Cardiovasc Thorac Surg. 2004;3:174-5.

5. Darwish BK, Kabbani SS. Giant substernal goiter with chylothorax. Asian Cardiovasc Thorac Ann. 2003;11:165-6.

6. Cagli K, Ulas MM, Hizarci M, Sener E. Substernal goiter: an unusual cause of respiratory failure after coronary artery bypass grafting. Tex Heart Inst J. 2005;32:224-7.

7. Sharma A, Naraynsingh $V$, Teelucksingh S. Benign cervical multi-nodular goiter presenting with acute airway obstruction: a case report. J Med Case Reports. 2010;4:258.

8. Kolawole IK, Rahman GA. Emergency thyroidectomy in a patient with severe upper airway obstruction caused by goiter: case for regional anesthesia. J Natl Med Assoc. 2006;98:86-9.

9. Aloumanis K, Mavroudis K, Vassiliou I, Arkadopoulos N, Smyrniotis V, Kontoyannis $\mathrm{S}$, et al. Urgent thyroidectomy for acute airway obstruction caused by a goiter in a euthyroid pregnant woman. Thyroid. 2006;16:85-8.

10. Gauger PG, Guinea Al, Reeve TS, Delbridge LW. The spectrum of emergency admissions for thyroidectomy. Am J Emerg Med. $1999 ; 17: 591-3$. 